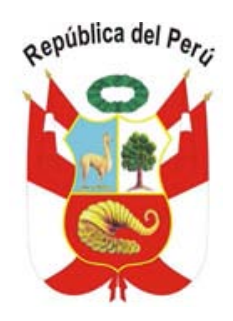

\title{
SEGUNDO CONGRESO INTERNACIONAL SOBRE JUSTICIA INTERCULTURAL EN COMUNIDADES ANDINAS Y RONDAS CAMPESINAS \\ "Construyendo un País con Justicia Social"
}

En Cajamarca, Provincia de Cajamarca, Departamento de Cajamarca, reunidos los jueces y juezas, y las autoridades de las rondas campesinas y comunidades andinas, expertos académicos nacionales e internacionales, convocados por el Poder Judicial, hemos arribado a las siguientes conclusiones y recomendaciones en el marco de un diálogo intercultural orientado a generar propuestas de coordinación entre la justicia ordinaria y la justicia indígena:

\section{CONCLUSIONES:}

1. Este Segundo Congreso viene a consolidar y ratificar las conclusiones y recomendaciones del Primer Congreso Internacional sobre Justicia Intercultural en Pueblos Indígenas realizado en la ciudad de La Merced Chanchamayo, por lo que constituye una renovación del compromiso del Poder Judicial para desarrollar este proceso de acercamiento y de encuentro entre la justicia ordinaria y la justicia especial comunal y ronderil en el marco del diálogo intercultural.

2. Reconocemos el importante papel que cumplen las comunidades y rondas campesinas en el ejercicio de sus funciones jurisdiccionales contribuyendo de esa forma al objetivo común de lograr la paz social y el mejor acceso a la justicia de la población rural.

3. Afirmamos la necesidad de construir procesos para que la justicia ordinaria y la justicia comunal y ronderil desarrollen mecanismos para promover relaciones de complementariedad y mutuo apoyo. 
Segundo Congreso Internacional sobre Justicia Intercultural en Comunidades Andinas y Rondas Campesinas

4. Ratificar el respeto y cumplimiento de la legislación nacional e internacional sobre los derechos de los pueblos indígenas y rondas campesinas a efectos de su debida observancia por las autoridades del sistema de justicia.

5. Reiteramos nuestro reconocimiento al papel protagónico desempeñado por el Doctor Javier Villa Stein, en su condición de Presidente del Poder Judicial, por haber propiciado la reflexión sobre la justicia intercultural en estos dos Congresos, y le solicitamos al Presidente Electo Doctor César San Martín Castro que continúe profundizando la agenda desarrollada en el marco del diálogo intercultural, entre la justicia ordinaria y justicia comunal.

\section{RECOMENDACIONES}

1. Fortalecer los mecanismos y criterios de coordinación entre los sistemas de justicia ordinaria y la justicia indígena en el marco de un diálogo intercultural, con participación de las autoridades de ambas jurisdicciones.

2. Solicitar al Congreso de la República la aprobación de la Declaración de las Naciones Unidas sobre los Derechos de los Pueblos Indígenas del 13 de Setiembre de 2007.

3. Crear una Oficina Nacional de Justicia Intercultural, dependiente del Poder Judicial, para desarrollar políticas de coordinación entre la jurisdicción estatal, comunal y ronderil.

4.- Generar espacios de formación, capacitación e intercambio de saberes con enfoque intercultural para los operadores de justicia ordinaria y de las autoridades de la jurisdicción indígena, con participación paritaria replicando la experiencia de los Centros de Justicia Intercultural de los Distritos Judiciales de San Martín y Cajamarca.

5. Recomendar a las autoridades educativas de todos los niveles de educación la creación de cursos que promuevan el estudio y la reflexión de la diversidad cultural del Perú con el fin de impulsar la comprensión intercultural en nuestra sociedad.

6. Recomendar que en las zonas declaradas en estado de emergencia se afirme la plena vigencia de los derechos humanos y, asimismo, se respete el derecho de las comunidades indígenas y rondas campesinas.

Cajamarca, 10 de diciembre de 2010 